\title{
Real-time observation of tsunami by RTK-GPS
}

\author{
Teruyuki Kato ${ }^{1}$, Yukihiro Terada ${ }^{2}$, Masao Kinoshita² ${ }^{2}$ Hideshi Kakimoto $^{2}$, Hiroshi Isshiki ${ }^{2}$, Masakatsu Matsuishi $^{3}$, \\ Akira Yokoyama ${ }^{3}$, and Takayuki Tanno ${ }^{3}$ \\ ${ }^{1}$ Earthquake Research Institute, University of Tokyo, Bunkyo-ku, Tokyo, Japan \\ ${ }^{2}$ Hitachi Zosen Corporation, Taisho-ku, Osaka, Japan \\ ${ }^{3}$ Hitachi Zosen Information Systems Co., Ltd., Ohta-ku, Tokyo, Japan
}

(Received January 6, 2000; Revised July 21, 2000; Accepted July 21, 2000)

\begin{abstract}
A new tsunami observation system has been developed, which employs the RTK-GPS technique to detect a tsunami before it reaches the coast. The system consists of dual-buoys: the Support-buoy, which is sensitive to wind-waves, and the Sensor-buoy, which is of a spar-type and is insensitive to wind-waves. Both buoys are equipped with a GPS antenna. An experiment using this system was carried out for about nine days in March 1999. Observation data were monitored at the onshore base station. The results showed that hourly averaged data is consistent with ocean tides for both buoys. The Sensor-buoy was found not to respond much to wind-waves compared to the Support-buoy. Thus, it may be preferable to use a spar-type buoy for detecting a tsunami efficiently. Furthermore, a simple frequency analysis showed that a tsunami could be easily separated from higher frequency wind waves if a tsunami is superimposed on regular wind waves.
\end{abstract}

\section{Introduction}

If a large tsunami is detected offshore and a warning is announced before its arrival at the nearby coast, the disastrous effects of the tsunami may be significantly reduced. A number of offshore tsunami detection systems have been developed which mostly use ocean bottom pressure gauges, from which data are transmitted through an ocean-bottom cable (e.g. Hino et al., 1998), or by satellite via acoustic transmission from the ocean bottom to the buoy (e.g. Gonzalez et al., 1999). We are developing a new tsunami detection system which employs a real-time kinematic (RTK) GPS system installed on a buoy, and is much more cost effective and robust relative to the alternative techniques.

The authors started the project in 1997 using a simple prototype buoy (Kato et al., 1998). Then a new experimental system was developed and an experiment using the new system in the open sea was carried out in March 1999. This paper briefly describes the system and the results of the experiments. A brief discussion is added concerning future possibilities for operational use and the problems that would need to be solved in such a case.

\section{Hardware System}

The current tsunami detection system employs real-time kinematic-GPS technology which monitors a moving platform in real-time with an accuracy of a few centimeters by relative positioning. If a GPS antenna is placed on top of a stable buoy at sea, the variations of the sea surface relative to a stable location on land can be monitored. Only the buoy's vertical motion is important for tsunami detection as well as

Copy right (c) The Society of Geomagnetism and Earth, Planetary and Space Sciences (SGEPSS); The Seismological Society of Japan; The Volcanological Society of Japan; The Geodetic Society of Japan; The Japanese Society for Planetary Sciences. other short period wind waves.

In the present experimental system dual GPS receiving systems are used: two GPS antennas on land and two on buoys. At the onshore base station, two GPS antennas are placed for reference purposes, and the base station has the function of real-time monitoring of the buoys. Sea level is measured by two buoy systems. Kelecy et al. (1994) and Born et al. (1994) used GPS buoys to detect sea level height, but their experiments were not designed to detect tsunamis, but to calibrate the ERS-1 and TOPEX/POSEIDON altimeter, respectively, for a short period of time. The present system aims to directly detect tsunamis and is required to operate for a long time.

In this experimental system, two kinds of buoy are tested: the Support-buoy and the Sensor-buoy. Designs for these buoys are shown in Fig. 1. GPS antennas are mounted at the top of each buoy. The Support-buoy is designed to move with wind-waves and is equipped with GPS receivers, a number of sealed lead batteries, a wind generator, solar panels for power supply, and a pair of radio receiver and transmitter devices. The Sensor-buoy is a spar-type buoy about $8 \mathrm{~m}$ long designed to be resistant to wind wave motion (e.g., Kelecy et al., 1994; Born et al., 1994). The center of mass of this spar-type buoy is located at several meters below the sea surface, so that the buoy reacts more to long frequency waves compared to the Support-buoy.

A schematic design of the deployment of the buoys at sea is shown in Fig. 2. In order for the Support-buoy not to float away or rotate, it has to be anchored by tri-directional sinkers. On the other hand, the Sensor-buoy, although connected to the Support-buoy with an antenna cable, should be free from any tension as much as possible, other than seasurface displacement. Thus, the Sensor-buoy is loosely tied 

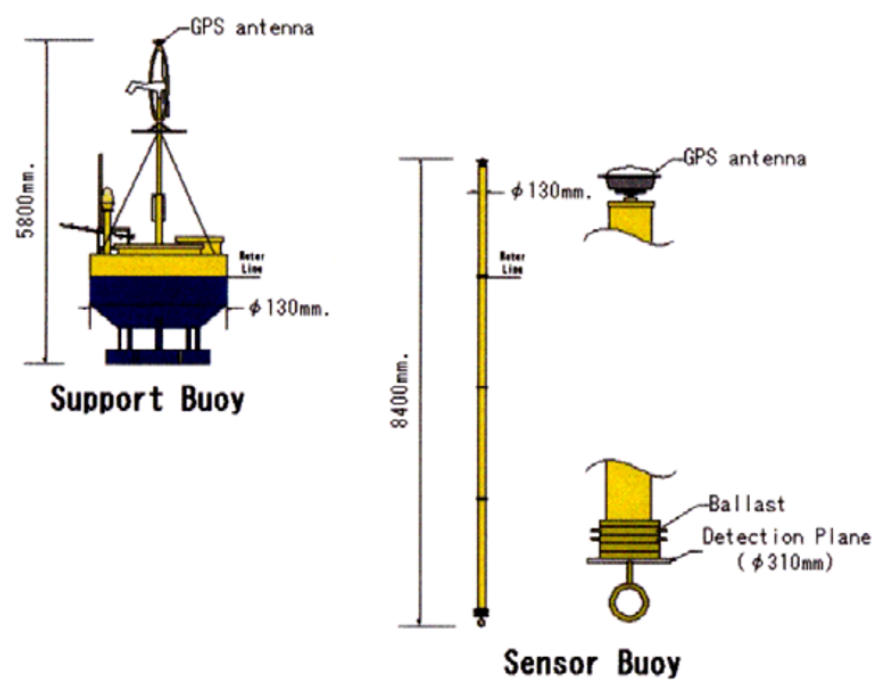

Fig. 1. Support-buoy (left) and Sensor-buoy (right). Sensor-buoy is insensitive to wind-waves compared to Support-buoy.
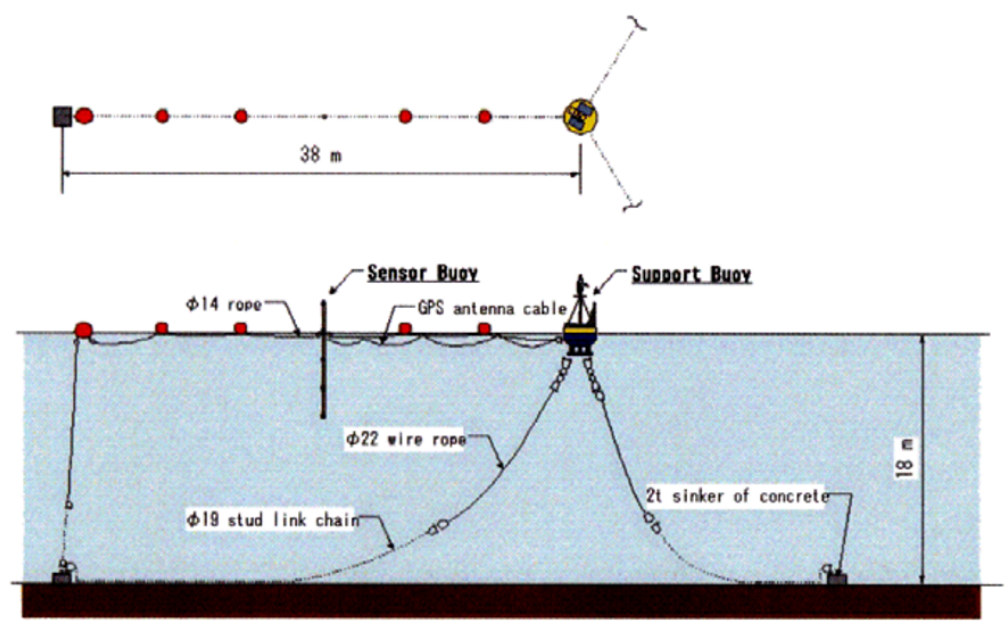

Fig. 2. Schematic design of the tsunami detection system. Wire is extended in both directions of the Sensor-buoy. The depth of water was about $18 \mathrm{~m}$ in the experiment.

to the supporting ropes. The float at the farthest end from the Support-buoy is anchored by a single sinker.

The data taken at the Support-buoy and the Sensor-buoy are first stored and processed in GPS receivers installed on the Support-buoy. Then the processed data are transmitted to the land base by $429 \mathrm{MHz}$ radio transmissions. The transmitted data (position of the GPS sensors) are monitored and stored in the PC at the base station.

Because the data is processed using the RTK software within the receiver, no correction for tropospheric or ionospheric effects could be applied. Thus, in this experiment, several kilometers would be the practical limit for distance from buoy to base station in order to achieve an accuracy of several centimeters.

This system is still experimental and no integrity monitoring is performed, as would be required during operational use. The improved system we are now preparing is planned to deploy such a monitor system for operational applications.

\section{Experiment}

The experiment was performed over nine days (March 1826, 1999) offshore of the Miura Peninsula, in the Sagami Bay, in central Japan. The buoy system was installed, as shown in Fig. 2, about $900 \mathrm{~m}$ from the land base and about $500 \mathrm{~m}$ offshore at a water depth of about $25 \mathrm{~m}$. GPS satellites were tracked every second.

The season was early spring and there were both calm and rough sea conditions. When the wind was strong, at about $30 \mathrm{~m} / \mathrm{s}$, and the surface was rough, the Support-buoy swayed heavily but the data were obtained without difficulty, and there were no radio transmission failures throughout the period of the experiment. A combination of wind generator and solar batteries was sufficient to charge the lead batteries in the Support-buoy. Thus real-time monitoring during the period was entirely successful. 


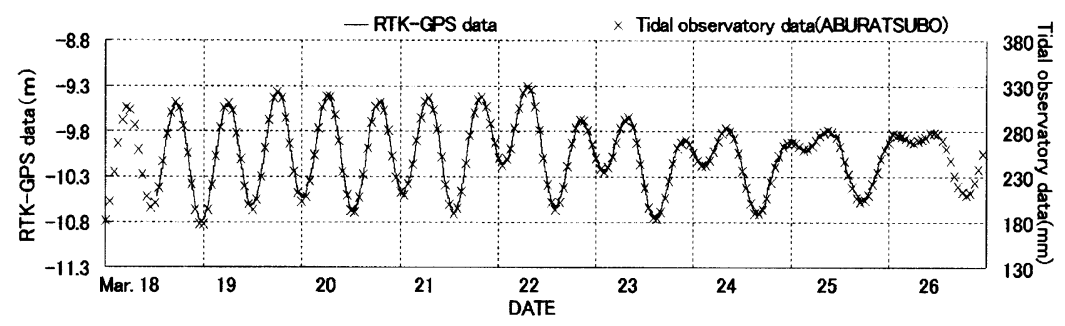

Fig. 3. Line drawing shows RTK-GPS data by Support-buoy, and cross marks show tidal observatory data at Aburatsubo tidal station.
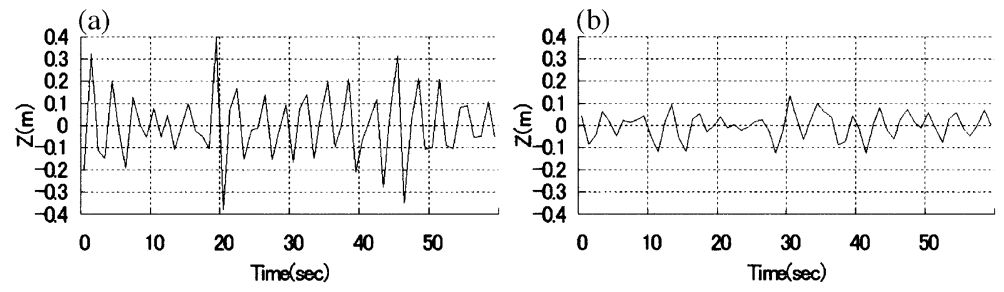

Fig. 4. A sample of observation data by (a) Support-buoy, and (b) Sensor-buoy at the same time period. Data were taken when the sea-surface was rough. Sampling interval is one second.
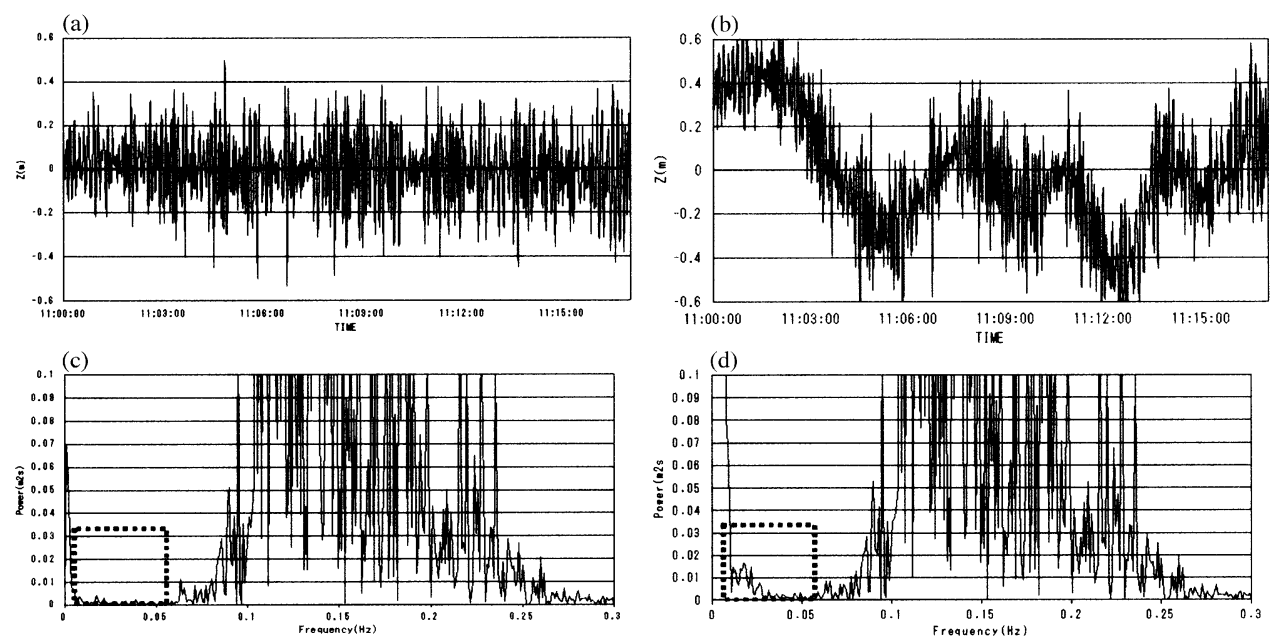

Fig. 5. (a) Measured data (b) Measured data + tsunami (c) FFT of measured data (d) FFT of tsunami data. Tsunami data were read manually from Nagai (1998).

\section{Results}

\subsection{Measurement of tide and wind-waves}

First, the data was examined in order to determine if it accurately traced the ocean tide variability. For this purpose, the sampled data from the tsunami meter were compared with data at the Aburatsubo tide-gauge station located about $1 \mathrm{~km}$ from the buoy. Figure 3 shows a comparison with hourly data at the Aburatsubo tide gauge shown by cross marks, whereas the line shows height change of the sea surface observed with the Support-buoy. Plot interval is 1 minute averaged for 60 points with a one second sampling, to average out wind-waves. There is no visible shift or offsets in the plots. Thus the data collected by the buoy system seems to track the change of sea-surface.

Figure 4 shows an example of a plot for a short period of data (10 minutes) observed at each buoy in the same time window. Plot interval is one second. As readily seen, the variability of the Sensor-buoy is significantly smaller than the wind-waves. Although a closer examination may have to be made, the Sensor-buoy seems not to respond to surface ripples and wind-waves, and reacts instead to the deeper part of the water mass, which is preferable for tsunami detection.

\subsection{Simulation for detection of tsunamis}

The present system demonstrated that it could track the sea-surface quite well. However, an important consideration is if the system would be able to detect a tsunami. Because tsunamis are not generated frequently, the authors have had to examine them by experimental means. One method is to simulate a real tsunami record and apply to a mathematical procedure to check if the tsunami signal could be detected embedded in the data for non-tsunami surface waves.

Data was taken for the Nihonkai-Chubu earthquake at Oga (Nagai, 1998). A record of tsunami data was added to the data under rough sea-surface circumstances. Figure 5(a) 
shows measured sea-surface changes for the Sensor-buoy. Figure 5(b) shows data added to simulate the tsunami, which is manually extracted from a publication of Nagai (1998). The real record of the present tsunami detection system may look like Fig. 5(b). As is readily seen in Fig. 5, a tsunami has a much longer period than wind waves, although there might be large variations in its period. Thus, differentiating tsunamis from wind waves may not be so difficult if applying some filtering technique such as the Fast Fourier Transformation (FFT) to the RTK directly, or in post-RTK results processing.

Figure 5(c) shows the frequency analysis (FFT) of the measured record in Fig. 5(a). There are no waves or noise in the frequency spectrum lower than $0.06 \mathrm{~Hz}$, which has a period of about 17 seconds (shown by the part surrounded by the square). Figure 5(d) shows the result of the FFT from Fig. 5(b), and includes both wind-wave and tsunami. It can be readily seen that energy appears in the lower frequency bands (in the dashed square). Thus, detection of tsunamis might be possible, if other energy sources of different causes do not contaminate the record.

\section{Discussion}

The goal is to detect tsunamis as far offshore as possible in order to provide an early warning system. To realize this goal, the system should be placed at least $10 \mathrm{~km}$ from the coast and the accuracy of height change measurements should be smaller than several centimeters.

When the characteristic wavelength of a tsunami is longer than the water depth, the tsunami propagates approximately with a velocity of $\sqrt{g h}$ where $g$ is gravity at the surface and $h$ is the depth of water, which gives about $100 \mathrm{~km} / \mathrm{h}$ at a water depth of $100 \mathrm{~m}$ and $200 \mathrm{~km} / \mathrm{h}$ at $300 \mathrm{~m}$ depth. Suppose the present system is placed $10 \mathrm{~km}$ from the nearest coast and the tsunami proceeds perpendicular to the coast, the tsunami may reach the coast several minutes after the tsunami passes the tsunami-meter. Because it may take at least a few minutes for the present system to detect the arrival of a tsunami, allowance of several minutes is marginal. Therefore, ideally the tsunami-meter needs to be placed more than 20 to 30 kilometers from the coast. If we use the so-called on-thefly (OTF) technique in RTK-GPS, however, it has a distance limit of about $10 \mathrm{~km}$ (or less) because the positioning accuracy becomes much worse if the baseline length exceeds this distance. Because the OTF technique uses combinations of satellite pairs for ambiguity fixing, the conditions of fixing ambiguities become much worse when the baseline exceeds $10 \mathrm{~km}$, because the path of a GPS signal propagates in different parts of the ionosphere and the troposphere. Colombo (1996) states that the positioning accuracy could be within several centimeters, even if the baseline exceeds $1000 \mathrm{~km}$ in length. His technique does not fix cycle ambiguities, and only a 'floating' solution is used with ionosphere-free observables. However, his technique has not yet been developed for real-time use (Colombo, personal communication). Tsujii et al. (1997), on the other hand, developed computer software for RTK-GPS that could be applied for several tens of kilometers in baseline length using a revised OTF algorithm. It will be necessary to implement one of the new ambiguity resolution algorithms in this system in the near future.
Another question that must be answered is what accuracy level is necessary for detecting tsunamis. The height of a tsunami, which may cause serious damage, may be only 10 $\mathrm{cm}$ high or so in the deep ocean. Tsunami height is greatly exaggerated when it approaches the coast due to the shallower water depth, and also due to the geometry of coastline. Therefore, it may be necessary to detect a tsunami that is not outstanding in the record but is hidden in the wind-waves if the sea surface is rough. If the present system is used for a short baseline of several kilometers, it would not be so difficult to reach this accuracy. However, the condition is more serious if the system is far from land, for example, several tens of kilometers.

The authors tested whether the current system could detect tsunamis using a manually extracted record of a real tsunami. This kind of simulation may not be sufficient to check the sensitivity of the system. Further experimental testing may have to be conducted to check the sensitivity of the system, in which the buoy is placed on a vibrating bed and the obtained record can be calibrated using an independent sensor attached to the bed. At an experiment in the sea, other independent sensors to measure the position of the buoy may have to be employed to compare the results, at least during the development phase. These kinds of experiments are being prepared for the future tests.

In addition to these requirements, the operational system should have integrity so that the system runs without human interaction for a long time, in the open sea, for example, for at least one year. Power supply reliability for long period operations, durability under bad weather and salt corrosion conditions, stability of radio transmissions, etc., are thus important. To overcome these problems, the authors are now conducting a long-term experiment of the system in Osaka Bay, in which the system floats and is tied to a harbor wall, so as to investigate problems and improve the design of the system.

Furthermore, if the system is to be used as an early warning system, an automatic detection algorithm should be developed. Currently, the Japan Meteorological Agency has a tsunami warning system based on the location and magnitude of earthquakes. If JMA judges an earthquake might cause a tsunami, an announcement is made to the local government through satellite transmissions. However, it is not sufficient to rely on this kind of detection system. There are cases of a tsunami striking without warning, as was experienced in the Chile earthquake in 1960. The best way to protect local residents against tsunamis is to directly observe anomalous changes in sea-level height.

Summing up, further studies should be made in order to make the system reliable and trustworthy. The current system is not a conclusive tsunami detection system. Not only hardware, but also the integrity monitor system and data transmission system, should be much improved. In addition, the algorithm for detecting a tsunami should be developed, based on real-time time series analysis techniques. Moreover, considering that tsunamis have a wide variety of periods, from about ten minutes to more than one hour depending on earthquake sources, propagation path and geographical conditions, extensive numerical simulations will need to be made in order to ensure that a reliable algorithm for automatic tsunami de- 
tection is developed. These studies are, however, left for the future.

\section{Conclusion}

The present article introduces a design for a tsunami detection system using real-time kinematic GPS. The system employs dual buoys. One is the Support-buoy, which carries two GPS receivers, power supply, wind generator, solar panels, radio receiving and transmitting equipment, as well as a GPS antenna. The other is the Sensor-buoy, which is a spar-type with a GPS antenna at the top and connected to the Support-buoy with an antenna cable.

Nine days of experimental data demonstrated that the system precisely tracks sea-level, when compared to tide-gauge data. The Sensor-buoy does not respond to short period windwaves compared to the Support-buoy, suggesting that a spartype buoy is preferable for detecting long period waves such as tsunami. Frequency analysis of the data after adding a real tsunami record to the observed RTK data suggests that it is feasible to detect a tsunami, because a tsunami has, in general, much lower frequency than wind-waves.

Although there are many other problems to be examined and solved, it would be desirable to develop this type of tsunami detection system, and implement it within an early warning system for residents of nearby coasts from the standpoint of tsunami disaster mitigation.

Acknowledgments. Mr. Tatsutoshi Takahashi, Earthquake Research Institute, the University of Tokyo, assisted the authors during the experiment at Aburatsubo. Personnel of the Geographical Survey Institute kindly provided tide-gauge data at the Aburatsubo tide-gauge station. Dr. JingPing Duan of Leica Geosystems and an anonymous reviewer gave useful comments to the authors to improve the manuscript. The research was supported by a GrantIn-Aid of the Ministry of Education, Sports and Culture (\#10354006 and \#11792031).

\section{References}

Born, G. H., M. E. Parke, P. Axelrad, K. L. Gold, J. Johnson, K. W. Key, D. G. Kubitschek, and E. J. Christensen, Calibration of the TOPEX altimeter using a GPS buoy, J. Geophys. Res., 99, 24517-24526, 1994.

Colombo, O., Long-distance kinematic GPS, Chapter 13, in GPS for Geodesy (2nd edition), edited by P. J. G. Teunissen and A. Kleusberg, pp. 537-567, Springer, 1996.

Gonzalez, F. I., E. N. Bernard, H. B. Milburn, and H. O. Mofjeld, Early detection and real-time reporting of deep-ocean tsunamis, Abstracts of IUGG99 in Birmingham, B.127, 1999.

Hino, R., T. Kanazawa, S. Sakai, Y. Tanioka, and K. Suyehiro, Tsunamis from an off-Sanriku and the Papua New Guinea earthquakes observed by ocean bottom tsunami measurement, Programme and Abstracts The Seismological Society of Japan, 1998, Fall Meeting P23, 1998 (in Japanese).

Kato, T., Y. Terada, M. Kinoshita, H. Isshiki, and A. Yokoyama, GPS Tsunami-kei no kaihatsu, Gekkan Kaiyo, Special Vol. 15, 38-42, 1998 (in Japanese).

Kelecy, T. M., G. H. Born, M. E. Parke, and C. Rocken, Precise mean sealevel measurements using the Global Positioning System, J. Geophys. Res., 99, 7951-7959, 1994.

Nagai, T., Okiai harou kansoku network ni yoru tsunami hakei kansoku, Gekkan Kaiyo, Special Vol. 15, 1998 (in Japanese).

Tsujii, T., M. Harigae, and M. Murata, The development of kinematic GPS software, KINGS, and its application to observations of the crustal movements in the Izu-islands area, J. Geod. Soc. Japan, 43(2), 91-105, 1997 (in Japanese with English abstract).

Teruyuki Kato (e-mail: teru@eri.u-tokyo.ac.jp), Y. Terada, M. Kinoshita, H. Kakimoto, H. Isshiki, M. Matsuishi, A. Yokoyama, and T. Tanno 